\title{
FORMAS ALTERNATIVAS DE JUSTICIA ${ }^{1}$ Daniel Delgado Saldívar
}

\section{Resumen}

Las coyunturas nacionales e internacionales, derivadas de la interacción economía-tecnología-sociedad, parecen haber provocado un aumento significativo de la ineficiencia de los operadores de justicia tradicional en muchos países, además de incentivar la estructuración de nuevas modalidades de tratamiento de conflictos y controversias. El gobierno mexicano ha disciplinado tales formas alternativas de Justicia a través de Leyes específicas, priorizando algunos mecanismos, cuyos requisitos, características y principales obstáculos se exponen en este trabajo.

\section{Introducción}

Durante las últimas décadas, la gran mayoría de los países ha pasado por cambios significativos, derivados de la interacción economía-tecnologíasociedad. Los reflejos de esos cambios son claros en aspectos como: reconfiguración de empleo y retiro, el reconocimiento de la diversidad, nuevas formas de generar riqueza en mercados y países y, principalmente, en la creciente incapacidad de los gobiernos para tipificar, detectar, inhibir, investigar y administrar justicia en conflictos, particularmente los conflictos penales.

La baja velocidad de reacción de los gobiernos generó en muchos países, inclusive México, una marcada pérdida de confianza en las instituciones que operan el sistema de justicia, que obtuvieron las peores evaluaciones en la medición de confianza institucional entre el público en general (CIDAC - Centro de Investigación para el desarrollo, A. C., 2016, p. 8). Ese escenario, sumado a

\footnotetext{
${ }^{1}$ Ensayo realizado para la asignatura Adecuación del Estado y la Administración Pública en México del Programa de Doctorado en Administración Pública, ISAPAC
} 
la casi inexistente flexibilidad del sistema de justicia penal, significó "la aplicación de penas de prisión y (...) la institucionalización del sistema carcelario", lo que generó la necesidad de desarrollar mecanismos alternativos que permitan un mejor desempeño y, al mismo tiempo, aligeren la carga de los operadores del sistema tradicional.

La justicia alternativa, en el derecho penal, se configura por los Mecanismos Alternativos de Solución de Conflictos Penales (MASCP), definidos como "cualquier proceso en el cual la víctima y el delincuente $\mathrm{y}$, cuando sea necesario, cualquier otro individuo o miembro de la comunidad afectada por el delito, participan de forma conjunta y activa en la resolución de conflictos derivados del delito, por lo general con la ayuda de un facilitador", según el Consejo Económico y Social de las Naciones Unidas (CIDAC - Centro de Investigación para el desarrollo, A. C., 2016, p. 11).

Así, el 29 de diciembre de 2014 se publicó en México, en el Diario Oficial de la Federación, la Ley Nacional de mecanismos alternativos de solución de controversias en materia penal. La Ley marca la oficialización de los mecanismos alternativos como instrumentos válidos para la justicia alternativa. Según la propia Ley lo establece, se pretende "propiciar, a través del diálogo, la solución de las controversias que surjan entre miembros de la sociedad", priorizando "procedimientos basados en la oralidad, la economía procesal y la confidencialidad" (Cámara de Diputados del H. Congreso de la Unión, 2014).

El camino para esa Ley fue preparado por la reforma del Artículo 17 de la Constitución Política de los Estados Unidos Mexicanos, realizada en el año 2008, que dispuso que "Las leyes preverán mecanismos alternativos de solución de controversias" (Congreso de la Unión, 2017). Todo indica que los mecanismos de justicia alternativa no solamente amplían el acceso a la justicia, sino que buscan transformar la estructura actual para que el acceso a la justicia no sea una excepción. 


\section{Desarrollo del Tema}

Aunque el derecho penal visualice la pena al ofensor como "readaptación" para su reintegración a la sociedad, la justicia tradicional la encara como retribución u castigo por la transgresión de la ley. Los mecanismos alternativos de solución de conflictos penales (MASCP) y los mecanismos derivados de ellos, aplicables en otras ramas del derecho, buscan no solamente reparar el daño sufrido por la víctima sino, también, que "el ofensor comprenda la inaceptabilidad de su conducta y entienda los efectos de la misma" (CIDAC - Centro de Investigación para el desarrollo, A. C., 2016, p. 12).

Con ese enfoque, la Ley Nacional optó por priorizar los mecanismos de: Conciliación, Mediación y Junta Restaurativa. Este último pretende obtener un acuerdo con base en el diálogo entre la víctima y el requerido, además de la familia y los amigos de cada uno. Naturalmente, la capacitación de los facilitadores es esencial, pues las habilidades específicas incluyen algunas poco convencionales, como: Lidiar con emociones, Propiciar el diálogo, escucha activa, Expresar apoyo y empatía y otras (CIDAC - Centro de Investigación para el desarrollo, A. C., 2016, p. 39).

Adicional a lo anterior, otra ventaja de los mecanismos alternativos de solución de controversias es que pueden ser más flexibles, rápidos, económicos y ágiles que los mecanismos tradicionales. Según el sitio Juiciosorales.mx, "es económico porque le permite evitar gastos de dinero que todo juicio requiere; es breve porque se resuelven los conflictos en poco tiempo a través de audiencias continuas; y ayuda a fortalecer las relaciones interpersonales pues las audiencias se realizan en el marco del respeto a la dignidad de ambas personas" (JuiciosOralesMX, 2017).

La situación ideal, naturalmente, sería que pocos asuntos llegaran a juicio, en procesos cortos y expeditos. Sin embargo, la modificación del proceso ni siempre es acompañada por la modificación de las actitudes. Tal modificación se vuelve más compleja cuando se analizan los principales factores opositores, según García Peña (García Peña, 2017). Tales factores son: (1) los profesionistas que defienden los intereses opuestos adoptan postura de 
combate, aspirando al vencimiento absoluto y no a la conciliación; (2) los ánimos de los opositores ya están alterados y exacerbados, inhibiendo el convencimientos cooperativo, pacífico y satisfactorio para ambas partes; y (3) el juez tiene como función resolver los asuntos judiciales, no conciliar intereses opuestos.

Con esos obstáculos, la aceptación de la Mediación depende de esfuerzos focalizados y direccionados para substituir los conceptos de "ganar-perder" por "ganar-ganar". En el caso específico de la Mediación, ésta requiere una tercera persona neutral que facilite la comunicación para que las partes lleguen a un acuerdo que resuelva la disputa, acelerando tal cambio de conceptos.

La mediación, como proceso informal, reduce significativamente el tiempo, los recursos y la complejidad de los juicios tradicionales. No solo eso, sino que también se aplica a conflictos de todo tipo: familiares, empresariales, entre países etc. En esencia, la mediación es un proceso privado, confidencial y, sobretodo, voluntario, en el que las funciones del mediador son diversas y focalizan la obtención de acuerdos mutuamente satisfactorios. Entre ellas: "Mitigar la beligerancia e instaurar una comunicación efectiva; realizar cuestionamientos que hagan emerger los verdaderos intereses de cada mediado; contribuir para que las partes conciban nuevas ideas y que puedan expresarlas; asegurar que las partes se encuentren receptivas a nuevos" etc. (Buenrostro Báez, 2017, p. 63).

La mediación, entonces, depende fuertemente de la preparación y la capacitación de los mediadores, los cuáles son vistos como los pivotes del cambio. Según lo especifica Buenrostro: "Adoptar el rol de facilitador (...) implica la transformación del mismo en el proceso penal, tarea harto difícil, pues se está hablando del cambio de mentalidad y actitud de toda una formación y práctica. Por lo tanto, el Ministerio Público deberá concretarse a su rol de autoridad judicial y a orientar, convencer y canalizar a las partes para que recurran a la justicia alternativa, pero no a conciliar o mediar directamente, pues esa es la función del facilitador especializado en mecanismos alternativos 
de solución de conflictos en los casos en que el Ministerio Público le derive el asunto" (Buenrostro Báez, 2017, pp. 258-259).

La Conciliación la define la Ley como "el mecanismo voluntario mediante el cual los Intervinientes, en libre ejercicio de su autonomía, proponen opciones de solución a la controversia en que se encuentran involucrados" (Cámara de Diputados del H. Congreso de la Unión, 2014, p. 7). En muchos aspectos operacionales, la Mediación y la Conciliación son sinónimos, variando únicamente en el protagonismo del facilitador en la Conciliación, que puede presentar, a las partes, propuestas para solucionar el conflicto.

El tercer mecanismo de la Ley, la Junta Restaurativa, es el establecimiento del diálogo y la construcción de acuerdos en conjunto por las partes y la comunidad involucrada. Así, la Junta restaurativa depende de la naturaleza del caso o del número de involucrados en el conflicto. También se requiere la participación de una persona facilitadora y el reconocimiento de responsabilidad por parte del ofensor. En la Junta restaurativa el foco deja de ser el castigo y el cumplimiento de las leyes, para pasar a ser la reparación de los derechos y las necesidades de las partes y las comunidades involucradas.

Uno de los principales puntos de la Ley es que si no se soluciona la controversia por alguno de los mecanismos alternativos, el facilitador puede sugerir que recurran a uno diverso. Además, en ningún caso se pierde el derecho de resolver la controversia por la vía legal. 


\section{Conclusiones}

Las formas alternativas de Justicia están en un proceso de implantación inevitable, dadas las características actuales y previstas del sistema tradicional de Justicia y sus operadores; sin embargo, los obstáculos representados por el necesario cambio de actitudes en los operadores y, sobre todo, la necesarísima capacitación de los facilitadores necesarios en todo el país provocarán una lentitud indeseada en el proceso de implantación, el cual probablemente solo dejará de ser "alternativo" para pasar a ser "obligatorio" a partir de la próxima genera

Bibliografia

Buenrostro Báez, R. (01 de diciembre de 2017). Justicia alternativa y el sistema acusatorio. Fonte: Universidad de Guadalajara/Laboratorio Juicios Orales:

http://148.202.89.14/laboratoriojuiciosorales/sites/default/files/bibliografia /DGEPN-16JusticiaAlternativaySistemaAcusatorio.pdf

Cámara de Diputados del H. Congreso de la Unión. (29 de diciembre de 2014). Ley nacional de mecanismos alternativos de solución de controversias en materia penal. Acesso em 01 de diciembre de 2017, disponível em Cámara de Diputados LXIII Legislatura: http://www.diputados.gob.mx/LeyesBiblio/pdf/LNMASCMP_291214.pdf

CIDAC - Centro de Investigación para el desarrollo, A. C. (2016). La otra Justicia; reporte sobre la operación de la justicia alternativa en México. México, D. F.: Cidac. Acesso em 01 de Diciembre de 2017, disponível em http://cidac.org/wp-content/uploads/2016/03/tinker.pdf

Congreso de la Unión. (2017). Constitución Política de los Estados Unidos Mexicanos. Ciudad de México: Editorial Porrúa.

García Peña, J. H. (01 de diciembre de 2017). Justicia alternativa en México: la mediación como fórmula alternativa de solución a través de la vía y uso de los ODR. Fonte: e-marc.net: http://e-marc.net/justicia-alternativa-enmexico-la-mediacion-como-formula-alternativa-de-solucion-a-traves-dela-via-y-uso-de-los-odr/

JuiciosOralesMX. (01 de diciembre de 2017). Soluciones Alternas y Formas de Terminación Anticipada. Fonte: JuiciosOralesMX: http://juiciosorales.mx/soluciones-alternas-y-formas-de-terminacionanticipada/ 